\title{
Pharmacological Characterization of Presynaptic Calcium Currents Underlying Glutamatergic Transmission in the Avian Auditory Brainstem
}

\author{
Shobhana Sivaramakrishnan and Gilles Laurent \\ Biology Division, California Institute of Technology, Pasadena, California 91125
}

\begin{abstract}
We used whole-cell patch-clamp techniques on presynaptic terminals and postsynaptic neurons of the glutamatergic magnocellularis synapse in the chick auditory brainstem to study the effects of $N, P$, and L-type calcium channel blockers directly on presynaptic calcium currents and transmitter release. Presynaptic calcium currents and transmitter release were unaffected by nifedipine, blocked partially by $\omega$-agatoxin IVA and completely by $\omega$-conotoxin GVIA. The presynaptic calcium current is a low voltageactivated, noninactivating current and its block by $\omega$-agatoxin IVA was not reversed by repeated depolarization of the presynaptic terminal. Thus, the presynaptic calcium current that underlies transmitter release at the chick magnocellularis synapse differs in some respects from $\mathrm{N}$ and P-type calcium currents described in vertebrate neuronal cell bodies.
\end{abstract}

[Key words: vertebrate CNS, chick nucleus magnocellularis, cochlear nucleus, glutamatergic transmission, presynaptic calcium current, w-agatoxin IVA, w-conotoxin GVIA]

The release of neurotransmitter from nerve terminals is triggered by calcium entry through voltage-activated calcium channels located in the presynaptic terminal (reviewed by Katz, 1969; Augustine et al., 1987). By determining the electrophysiological properties of presynaptic calcium channels, onc may better understand the pattern of calcium entry into the nerve terminal, and thereby one of the essential steps in the release of transmitter and its modulation.

The nature of the presynaptic calcium current that underlies release from nerve terminals has been examined at the squid giant synapse (Llinás et al., 1981a,b; Charlton et al., 1982; Augustine et al., 1985a,b; Charlton and Augustine, 1990), the calyx synapse in the chick ciliary ganglion (Stanley and Goping, 1991; Stanley, 1993; Yawo and Momiyama, 1993) and the rat neurohypophysis (Lemos et al., 1994). In the vertebrate CNS, most presynaptic terminals at fast synapses are inaccessible, and calcium channels underlying transmitter release have been studied indirectly, by focussing on the effects of known calcium channel

\footnotetext{
Received Mar. 15, 1995; revised May 25, 1995; accepted May 26, 1995.

This work was supported by NIMH and Searle and McKnight Scholars awards to G.L. We thank M. Konishi, L. O. Trussell, and S. Zhang for valuable discussions during this work and M. S. Brodwick, H. Lester, E. M. Schuman, and two anonymous reviewers for critical reading of this manuscript.

Correspondence should be addressed to Dr. Shobhana Sivaramakrishnan, Department of Physiology and Biophysics, Mayo Clinic, 1-117 Medical Sciences Building, Rochester, MN 55905.

Copyright $(\mathcal{C} 1995$ Society for Neuroscience 0270-6474/95/156576-10\$05.00/0
}

blockers on the postsynaptic response to released transmitter. Such studies have been conducted at intact synapses (Takahashi and Momiyama, 1993; Regehr and Mintz, 1994; Wheeler et al., 1994a), in synaptosomes (Turner et al., 1992), or at synapses in culture (Pfrieger et al., 1992). These studies suggest that calcium channels sensitive to $\omega$-conotoxin GVIA ( $\omega$-CgTx GVIA) or $\omega$-agatoxin IVA ( $\omega$-Aga IVA) are involved in transmitter release at vertebrate central synapses. In the absence of direct measurements of presynaptic calcium currents, however, it is still unknown whether calcium channels in nerve terminals in the vertebrate CNS behave in a manner similar to those in neuronal cell bodies, where they have been well characterized (Mintz et al., 1992a), but where their exact function often remains unclear. While imaging techniques have been used at vertebrate central synapses to measure changes in presynaptic calcium concentration (Wu and Saggau, 1994), they were unable to provide an accurate description of the kinetics of the presynaptic calcium current.

To examine the nature of the presynaptic calcium channels that underlie transmitter release at synapses in the vertebrate $\mathrm{CNS}$, we used a brain slice preparation of the glutamatergic magnocellularis synapse in the chick auditory brainstem. The magnocellularis synapse is formed between large calyx-shaped nerve endings of auditory nerve afferents and the soma of neurons in the cochlear nucleus magnocellularis (NM) (Fig. 1A). There is no evidence of gap junctions at this synapse (Parks, 1981; Jhaveri and Morest, 1982; Rubel and Parks, 1988). This synapse is specialized to transmit the phase information and filter out the intensity information carried by incoming VIIIth nerve spike trains (Takahashi et al., 1984). Transmission at this synapse is fast, and the postsynaptic response is mediated mainly by AMPA receptors and to a lesser extent by NMDA receptors (Nemeth et al., 1983, 1985; Trussell et al., 1993; Zhang and Trussell, 1994).

We used whole-cell patch-clamp recordings (Hamill et al., 1981) from the presynaptic terminal and postsynaptic neuron to record calcium currents and measure transmitter release directly. The specific calcium channel blockers $\omega$-Aga IVA, $\omega$-CgTx GVIA, and nifedipine were used to identify the presynaptic calcium channels and characterize the calcium currents that trigger transmitter release at this synapse. We find that transmitter release at the chick magnocellularis synapse is triggered by a presynaptic calcium current sensitive mainly to $\omega$-CgTx GVIA and only partially to $\omega$-Aga IVA. The pharmacological and electrophysiological properties of the presynaptic calcium current differ from those of calcium currents in neuronal cell bodies and from those at other synapses studied so far. 

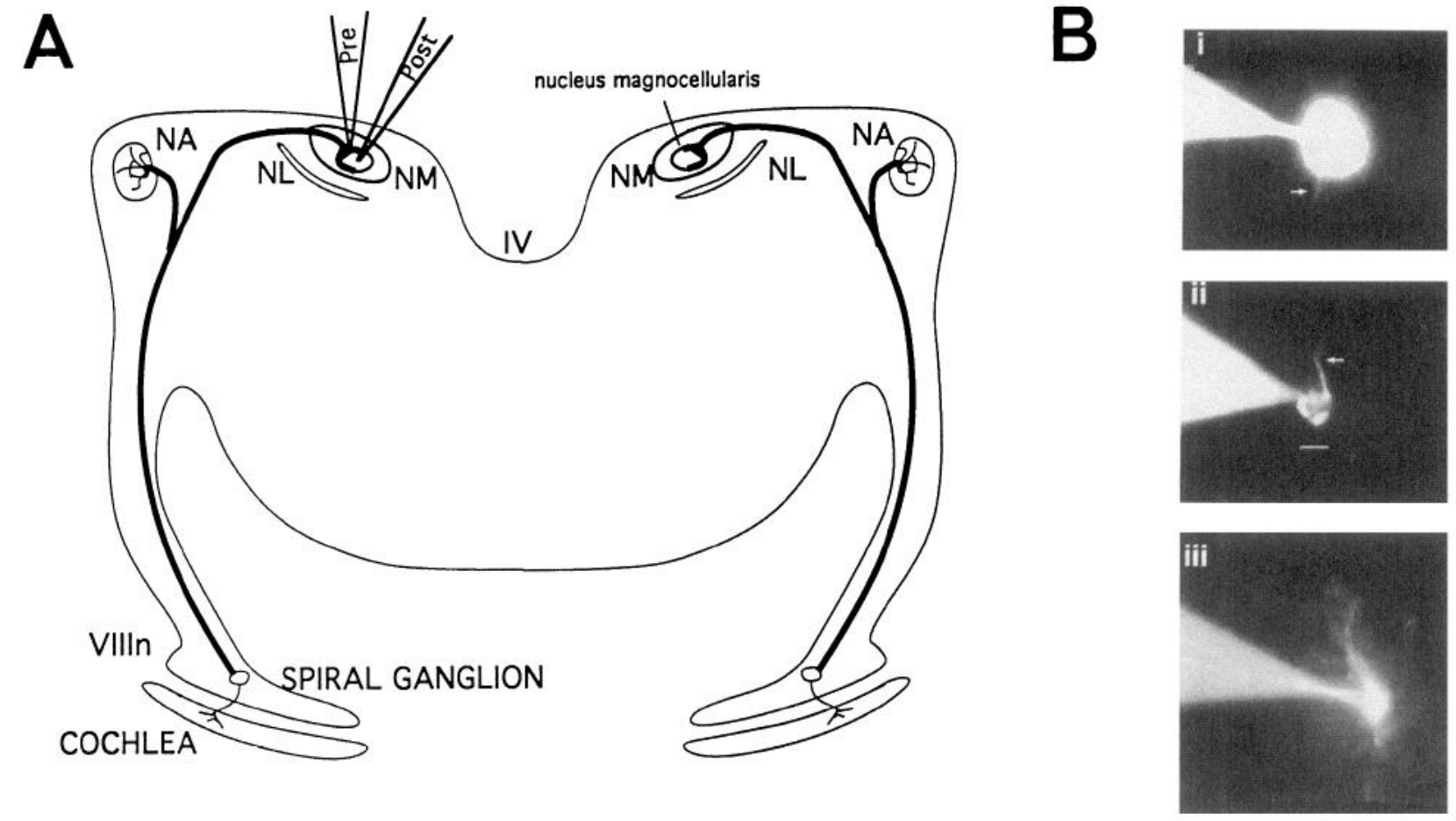

Figure 1. A, Schematic drawing of a slice through the chick cochlear nuclei. VIIIn, VIIIth nerve; $N A$, nucleus angularis; $N L$, nucleus laminaris; $N M$, nucleus magnocellularis; $I V$, IVth ventricle; PRE, presynaptic whole-cell patch electrode; POST, postsynaptic patch electrode. $B$, Lucifer yellow-fills of NM neuron (i) calyx terminal of an VIIIth nerve afferent (ii), and glial cell in NM (iii). Arrows point to axon of postsynaptic neuron (i) and presynaptic afferent (ii). Scale bar, $10 \mu \mathrm{m}$.

\section{Materials and Methods}

White Leghorn chick embryos were used at days E18-20; 200-300 $\mu \mathrm{m}$ thick coronal slices were cut through the brainstem (Fig. 1A) and stored in oxygenated chick saline. Experiments were carried out at $35^{\circ} \mathrm{C}$. A fixed-stage Zeiss microscope (Axioskop) fitted with a long working distance $40 \times$ water-immersion objective and Nomarski optics was used to view the slice. Whole-cell patch-clamp recordings (Hamill et al., 1981) were made from calyces and NM neurons on the surface of the slice (Fig. 1A). Recordings were made with an Axopatch-1D amplifier (Axon Instruments). Currents were leak-subtracted and filtered at $10 \mathrm{kHz}$. Data were collected for later analysis on an IBM clone microcomputer equipped with a TL-1 Interface and PClamp software (Axon Instruments). Borosilicate glass patch pipettes were uncoated and had DC resistances of 8-10 M $\Omega$. Uncompensated series resistances were 10-25 $\mathrm{M} \Omega$ and were compensated by about $80 \%$ and monitored during each experiment. Only those experiments during which the series resistance did not change by more than $30 \%$ were included for analysis.

Standard internal solutions contained, in mM: $130 \mathrm{~K}$ gluconate, 10 HEPES, $5 \mathrm{NaCl}, 1 \mathrm{MgCl}_{2}, 5 \mathrm{MgATP}, 11$ EGTA, $1 \mathrm{CaCl}_{2} ; \mathrm{pH} 7.3$ with $\mathrm{KOH}$. The external solution was composed of, in mM: $140 \mathrm{NaCl}, 5$ $\mathrm{KCl}, 5 \mathrm{CaCl}_{2}, 1 \mathrm{MgCl}_{2}, 10$ HEPES, 20 glucose; $\mathrm{pH} 7.3$ with $\mathrm{NaOH}$. For measurements of presynaptic calcium currents, internal solutions contained, in mM: $120 \mathrm{Cs}$ gluconate, $20 \mathrm{TEA}-\mathrm{Cl}, 11 \mathrm{EGTA}, 1 \mathrm{CaCl}_{2}$, 10 HEPES, $1 \mathrm{MgCl}_{2}, 5 \mathrm{MgATP}, 0.3 \mathrm{GTP}$; $\mathrm{pH} 7.3$ adjusted with $\mathrm{CsOH}$. The composition of the external solution was, in mM: $140 \mathrm{TEA}-\mathrm{Cl}, 5$ 4-AP, $0.5 \mu \mathrm{M}$ TTX, 20 HEPES, 20 glucose, $1 \mathrm{MgCl}_{2}, 5 \mathrm{CaCl}_{2}$; $\mathrm{pH} 7.3$ adjusted with TEA-OH. In some experiments, the internal patch pipette solution also contained $0.2 \%$ Lucifer yellow (Aldrich Chemicals). Stock solutions of $\omega$-CgTx GVIA (Peninsula Laboratories, California and Sigma Chemicals) and $\omega$-Aga IVA (Alomone Laboratories, Israel) were diluted to appropriate concentrations in saline containing $1 \mathrm{mg} / \mathrm{ml}$ cytochrome $\mathrm{C}$ just before the experiment. Stock solutions of nifedipine (Sigma Chemicals) were made in ethanol and the final concentration of ethanol in the bathing medium was $0.01 \%$. Cytochrome $\mathrm{C}$ and ethanol had no effect on synaptic transmission. Toxins were applied to the bath (bath vol. $=1 \mathrm{ml}$ ) with Hamilton syringes and bath perfusion was maintained at $1 \mathrm{ml} / \mathrm{min}$ during toxin application.

\section{Results}

Figure $1 B$ shows Lucifer yellow fills of a NM neuron (Fig. 1Bi), the presynaptic calyceal terminal of an VIIIth nerve afferent (Fig. 1Bii), and a glial cell (Fig. 1Biii) in the rostral region of the nucleus. At this embryonic stage, NM neurons have ovoid cell bodies with few dendrites (Fig. 1Bi). Each NM neuron receives a maximum of two nerve terminals on its soma (Jhaveri and Morest, 1982; Rubel and Parks, 1988). Presynaptic calyces varied greatly in appearance, but were always found tightly apposed to the NM soma. They sometimes appeared as crescentshaped structures along one "side" of the NM soma, or formed a cap or calyx which covered about a third of the NM soma surface. Glial cells, by contrast, were found close to, but not tightly apposed to NM cells. Their somata appeared round or oval and had clear processes spanning two or three NM cell bodies (Fig. 1Biii).

\section{Effects of calcium channel antagonists on transmitter release}

Transmitter release was evoked by extracellular stimulation of single VIIIth nerve afferent axons with a glass pipette. Excitatory postsynaptic currents (EPSCs) were measured with wholecell patch electrodes from the soma of NM neurons. In normal external saline, EPSCs were generally 4-8 $\mathrm{nA}$ in amplitude at a holding potential of $-70 \mathrm{mV}$, reached their peak values in less than $0.5 \mathrm{msec}$ and had a fast decay time constant of about 1 msec (see also Trussell et al., 1993). EPSC amplitudes were stable, decreasing by $10-15 \%$ of their original value $30 \mathrm{~min}$ after first establishing the whole-cell recording. In some experiments, active responses, probably due to imperfect voltage control of the NM soma and proximal axon, were superimposed on the 


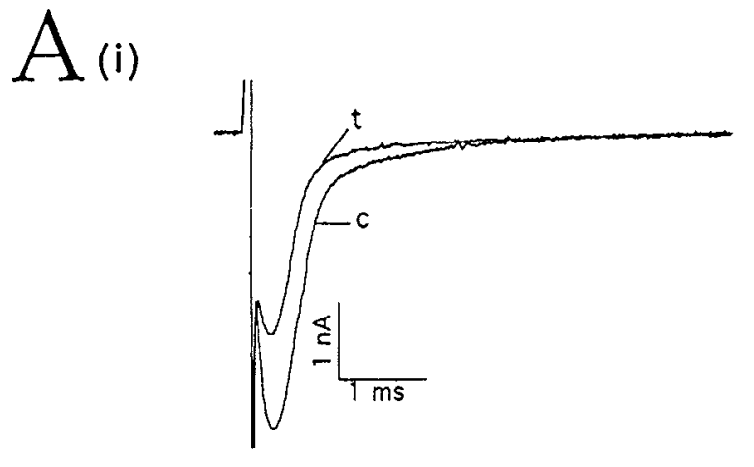

$\mathrm{B}$ (i)

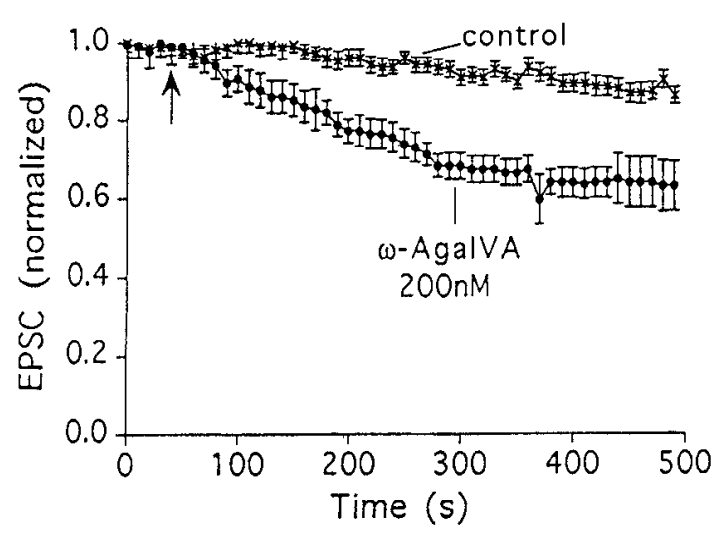

(ii)

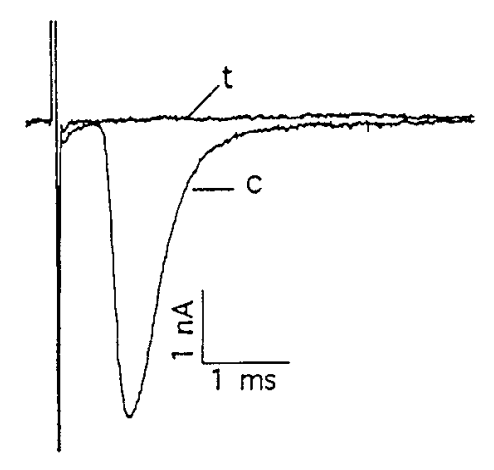

(ii)

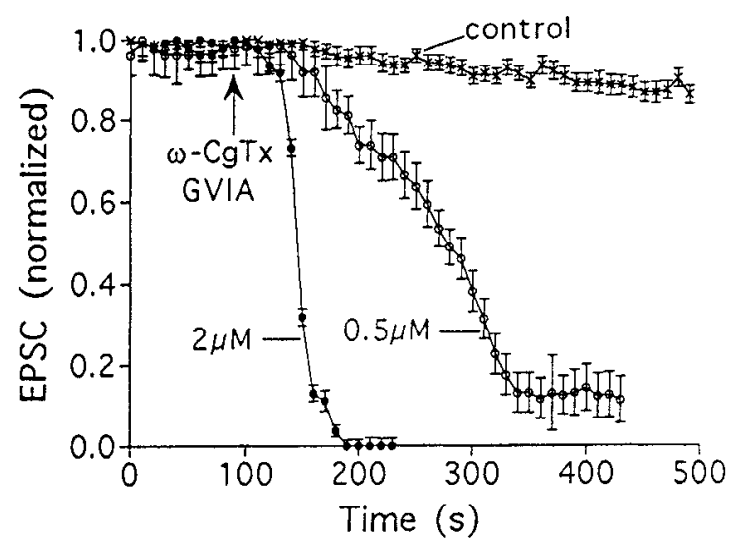

Figure 2. Effects of $\omega$-Aga IVA and $\omega$-CgTx GVIA on EPSCs. A, Effects of $200 \mathrm{~nm} \omega$-Aga IVA (i) and $2 \mu \mathrm{M} \omega$-CgTx GVIA (ii) on EPSCs evoked by stimulation of a single presynaptic afferent. $c=$ control EPSC, $t=6 \mathrm{~min}$ after $\omega$-Aga IVA application $(i)$ and 4 mins after $\omega$-CgTx GVIA application (ii). $B$, Time course of effects of $\omega$-Aga IVA ( $i$ ) (average of 4 experiments) and $\omega$-CgTx GVIA (ii) (average of 15 experiments for 2 $\mu \mathrm{M}$ and 3 experiments for $0.5 \mu \mathrm{M}$ ) on EPSCs. Arrow points to time of toxin application. The bathing solution contained $50 \mu \mathrm{M}$ bicuculline and 2 $\mu \mathrm{M}$ strychnine to block IPSCs caused by inadvertent stimulation of inhibitory fibers. Transmitter release was evoked by stimulating the presynaptic axon once every $10 \mathrm{sec}$. Error bars are SEMs.

falling phase of the EPSC. These experiments were not included for analysis.

We examined the effects of the calcium channel blockers nifedipine, $\omega$-Aga IVA, and $\omega$-CgTx GVIA on EPSC amplitudes; $10 \mu \mathrm{M}$ nifedipine had no effect on the EPSC. Its effect on the presynaptic calcium current could not be distinguished from rundown of the current (data not shown), suggesting that L-type channels (Fox et al., 1987) are not present in the presynaptic membrane. Figure 2 shows the effects of $\omega$-Aga IVA and $\omega$-CgTx GVIA on EPSCs. The EPSC was reduced by $34 \% \pm$ $5 \%$ ( $n=4$ animals) by $200 \mathrm{nM} \omega$-Aga IVA (Fig. $2 A i, B i$ ). Increasing the concentration of $\omega$-Aga IVA up to $1 \mu \mathrm{M}$ had no further effect. The remaining EPSC was blocked completely by $500 \mathrm{~nm} \omega$-CgTx GVIA. In the absence of $\omega$-Aga IVA, 1-2 $\mu \mathrm{M}$ $\omega$-CgTx GVIA produced complete block of the EPSC (Fig. 2Aii,Bii), while 500 nM $\omega$-CgTx GVIA blocked it by $90 \%$ (Fig. 2 Bii). The block by $\omega$-CgTx GVIA was not reversed by prolonged washing with normal saline. In some experiments, the effect of $\omega$-Aga IVA showed a limited reversibility, but the extent of reversal varied (between $5-15 \%$ ). Thus, the calcium channels underlying transmitter release at the chick magnocellularis synapse appear to be dihydropyridine-insensitive and sensitive to $\omega$-CgTx GVIA and $\omega$-Aga IVA.

In order to determine whether the block of the EPSC by $\omega$-Aga IVA and $\omega$-CgTx GVIA resulted partly from an effect of these toxins on the postsynaptic glutamate receptors, we examined the effects of $\omega$-Aga IVA and $\omega$-CgTx GVIA on the amplitude distribution of spontaneous miniature excitatory postsynaptic currents (MEPSCs) recorded from NM neurons. MEPSC frequency varied between $0.5-1 / \mathrm{sec}$ in different preparations. MEPSCs typically exhibited broad amplitude distributions, skewed towards low amplitudes, with the majority of MEPSCs being 30-40 pA in amplitude (see also Trussell et al., 1993). An EPSC ( $\sim 4 \mathrm{nA}$ ) evoked by a single action potential would thus comprise of, on average, 100 MEPSCs. Figure 3 shows the effects of bath application of these toxins on MEPSC amplitudes in experiments carried out in two different slices. MEPSCs were continuously recorded in saline for about $10 \mathrm{~min}$ before the toxin was applied to the bath. Following toxin application, recording of MEPSCs continued until the seal deteriorated, which was usually after a further $20 \mathrm{~min}$. $\omega$-Aga IVA and $\omega$-CgTx GVIA had no significant effects on the amplitude distribution, indicating that their effects on transmitter release had a presynaptic origin.

\section{Effects of calcium channel antagonists on the presynaptic calcium current}

We determined the sensitivity of the presynaptic calcium current to $\omega$-CgTx GVIA and $\omega$-Aga IVA. Two types of presynaptic depolarizations were used to evoke calcium currents. First, pre- 


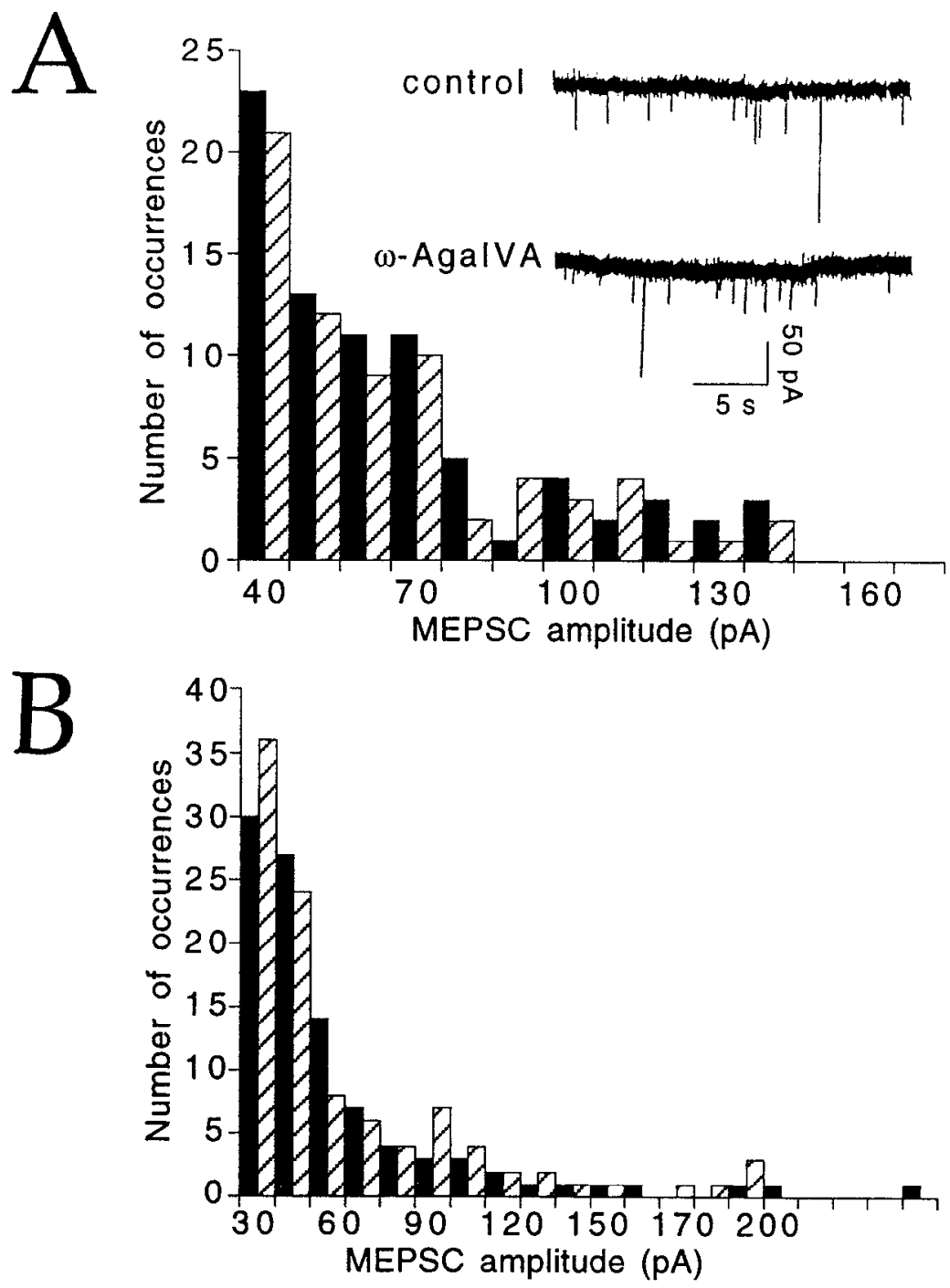

Figure 3. Effects of $200 \mathrm{~nm} \omega$-Aga IVA $(A)$ and $1 \mu \mathrm{M} \omega$-CgTx GVIA $(B)$ on MEPSCs. The postsynaptic neuron was held at $-70 \mathrm{mV}$ and MEPSCs were recorded in saline containing 1 $\mu \mathrm{M}$ tetrodotoxin to block spontaneous presynaptic action potentials and 50 $\mu \mathrm{M}$ bicuculline and $2 \mu \mathrm{M}$ strychnine to block the effects of spontaneous release from inhibitory nerve terminals on the NM neuron. Solid bars in the histograms in $A$ and $B$ indicate MEPSCs recorded in control conditions, stippled bars in the presence of the toxin. The inset in $A$ is a segment of raw traces in control conditions and 4 min after application of $200 \mathrm{nM} \omega$-Aga IVA. The histograms in $A$ and $B$ were constructed by counting all the MEPSCs for $5 \mathrm{~min}$ before toxin application and $6.5 \mathrm{~min}$ following toxin application. The bin width is $10 \mathrm{pA}$.

synaptic calcium currents were evoked with conventional step depolarizations of the terminal; $200 \mathrm{nM} \omega$-Aga IVA and $2 \mu \mathrm{M}$ $\omega$-CgTx GVIA respectively reduced the peak step-evoked presynaptic calcium current by $25 \% \pm 10 \%(n=4)$ and $100 \%$ ( $n$ $=8$ ) (Fig. 4Ai,ii, C). Sequential administration of $200 \mathrm{~nm} \omega$-Aga IVA and $2 \mu \mathrm{M} \omega$-CgTx GVIA to the same presynaptic calyx resulted in complete block of the calcium current $(n=4$; Fig. $4 B)$.

Second, presynaptic calcium currents were evoked by depolarizing voltage ramps which resembled the presynaptic action potential waveform (for example, see Fig. 7Ai). The contribution of different types of calcium channels to the total presynaptic calcium influx that precedes transmitter release may depend on the duration of the depolarization that activates them (McCobb and Beam, 1991). Thus, an action potential-like depolarization gives a physiologically more relevant estimation than longer step depolarizations would of the contribution of $\omega$-CgTx GVIA and $\omega$-Aga IVA-sensitive components to the total calcium influx that precedes transmitter released by a natural action potential. This is especially important in this study, because EPSCs were evoked by presynaptic action potentials rather than longer step depolarizations of the calyx (Fig. 2). With ramp depolarizations, the calcium current was exclusively a "tail" current. Tail currents were blocked to different extents by $\omega$-Aga IVA and
$\omega$-CgTx GVIA (Fig. 5); 200 nM $\omega$-Aga IVA had a small effect on the peak tail current, blocking it by $16 \% \pm 4 \%(n=4)$ (Fig. $5 A i, B i)$. Sequential application of $200 \mathrm{nM} \omega$-Aga IVA and $2 \mu \mathrm{M}$ $\omega$-CgTx GVIA resulted in complete block of the calcium current (Fig. 5Ai). In the absence of $\omega$-Aga IVA, $500 \mathrm{~nm} \omega$-CgTx GVIA reduced the tail current by $55 \% \pm 10 \%(n=5)$ (Fig. 4Aii,Bii) and $1 \mu \mathrm{M} \omega$-CgTx GVIA blocked it completely (Fig. 5Aiii).

Comparison of the presynaptic calcium current with $N$ - and $P$-type currents

Since $\omega$-CgTx GVIA and $\omega$-Aga IVA block N and P-type calcium channels in other preparations (Mintz et al., 1992a; Pfrieger et al., 1992), we were interested in knowing in what ways the calyx calcium current resembled or differed from $\mathrm{N}$ and P-type currents. A single characteristic feature of $\omega$-CgTx GVIA-sensitive N-type currents is their high activation threshold which is around $-30 \mathrm{mV}$ (Fox et al., 1987; Stanley and Goping, 1991; Yawo and Momiyama, 1993), and neuronal P-type channels show a relief of block by $\omega$-Aga IVA upon repeated depolarization of the membrane during toxin application or during the washout process (Mintz et al., 1992a). We found that, in these two respects, the calyx calcium current differed from $\mathrm{N}$ and P-type calcium currents. The presynaptic calcium current activated at ca. $-50 \mathrm{mV}$ from a holding potential of $-70 \mathrm{mV}$ 


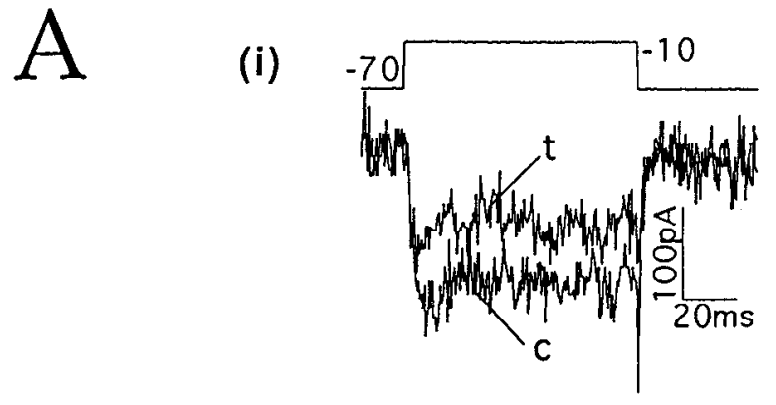

B

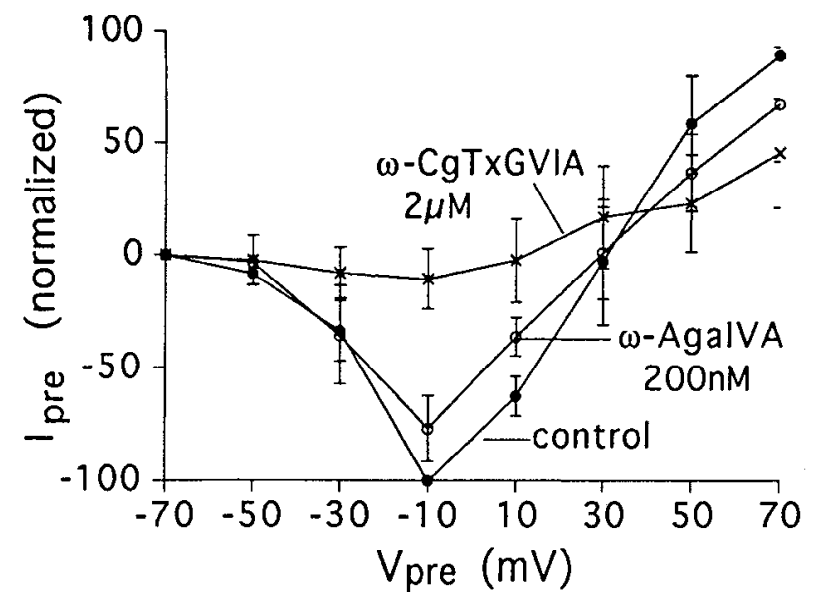

(ii)
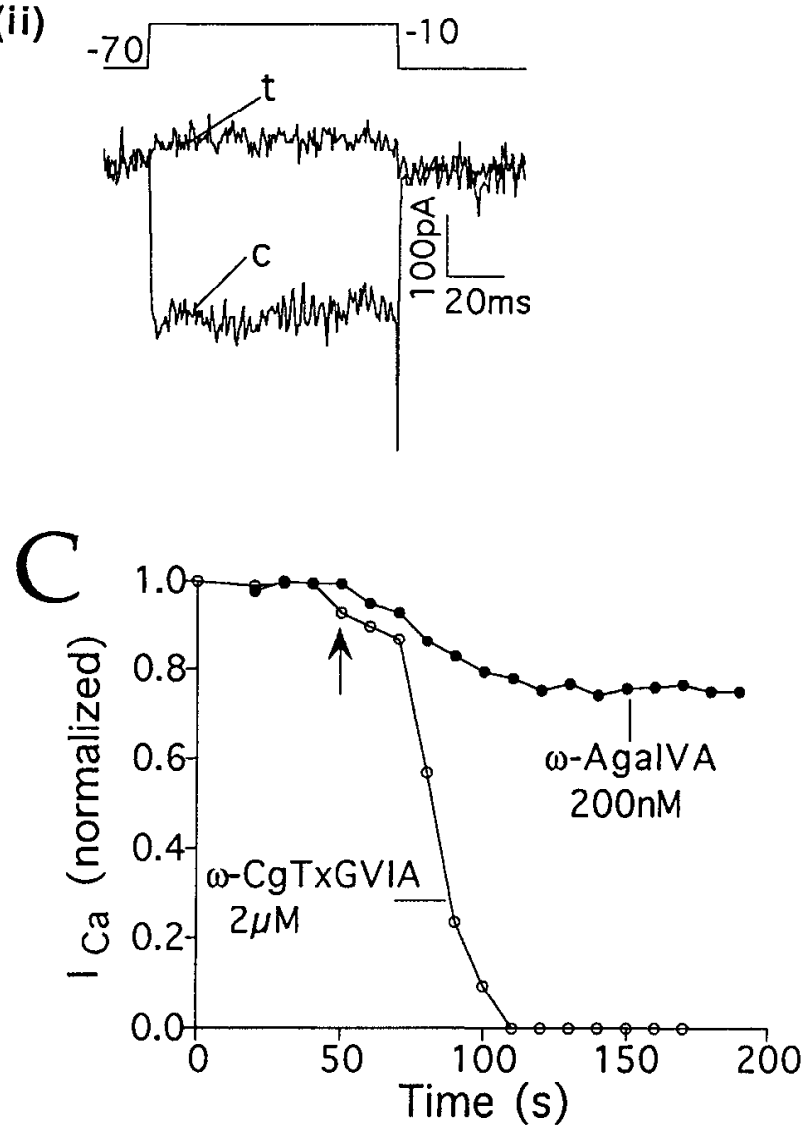

Figure 4. Effects of $\omega$-Aga IVA and $\omega$-CgTx GVIA on calyx calcium currents. $A$, Effects of 200 nim $\omega$-Aga IVA $(i)$ and $2 \mu$ M $\omega$-CgTx GVIA (ii) on calcium currents evoked by $100 \mathrm{msec}$ long depolarizing steps. $c$, control current; $t$, current in toxin, shown 3 min after application of 200 nM $\omega$-Aga IVA $(i)$ and 2 min after application of $2 \mu \mathrm{M} \omega$-CgTx GVIA (ii). $B, I-V$ curves of the peak calcium current resulting from sequential addition of $200 \mathrm{nM} \omega$-Aga IVA and $2 \mu \mathrm{M} \omega$-CgTx GVIA to the same presynaptic calyx. Each curve is an average of the $I-V$ curves from three calyces. Error bars are SEMs. $C$, Time course of toxin effect on the calcium current in two different calyces. Rundown of the current has been subtracted from each curve. Arrow points to time of application of toxin.

(Fig. 6Ai,ii) and reached its maximum amplitude at ca. $-10 \mathrm{mV}$ in less than $2 \mathrm{msec}(n=27$; Fig. $6 A i)$. The current showed little voltage- and time-dependent inactivation, as indicated by the monotonic increase in the amplitude of tail currents with increasing depolarization (Fig. 6Ai,ii). Similar monotonic increases occurred in both $3 \mathrm{~mm}$ and $5 \mathrm{mM}$ external calcium concentrations (data not shown), suggesting a lack of calcium-dependent inactivation in this physiological range of calcium concentrations. To compare the characteristics of the $\omega$-Aga IVA component of the calyx calcium current with those of P-type currents in mammalian neurons (Mintz et al., 1992a), we attempted to reverse the block of the calcium current by repeated depolarizations of the presynaptic terminal during washout of the toxin. Figure $6 B$ shows the calcium current in one presynaptic terminal, during application of $200 \mathrm{nM} \omega$-Aga IVA and subsequent depolarization during washout of the toxin. The block by $\omega$-Aga IVA could not be reversed by repeated stimulation of the presynaptic terminal to potentials ranging from +50 to $+100 \mathrm{mV}$ (holding potential $=-70 \mathrm{mV}$ ) during washout of the toxin $(n=3)$.

\section{Effects of calcium channel antagonists on action potentials}

Because the effects of the toxins on EPSCs were determined in conditions where the sodium and potassium currents were not blocked (Fig. 2), it is possible that the toxins affected EPSCs by affecting some components of these currents in addition to the calcium channels opened by the action potential. We therefore examined the effects of these toxins on the waveform of presynaptic and postsynaptic action potentials under current-clamp conditions (Fig. 7). Action potentials in the calyx were evoked either by stimulation of the presynaptic axon with an extracellular glass pipette or by injecting current pulses into the calyx through the recording whole-cell patch electrode. Extracellular stimulation produced one orthodromic action potential for each stimulus (Fig. 7Ai), while current injection caused repetitive spiking of the calyx (Fig. 7Aii); $2 \mu \mathrm{M} \omega$-CgTx GVIA and 200 nM $\omega$-Aga IVA had no significant effect on the amplitude or duration of action potentials in the calyx (Fig. 7Ai, ii) or NM neurons (Fig. 7Bi,ii). Thus the effect of the toxins appears to be confined to presynaptic calcium channels. The lack of toxin effect on the presynaptic action potential also suggests that the calcium influx that triggers transmitter release in response to a presynaptic action potential at the magnocellularis synapse must occur mainly at the end of or just after the presynaptic action potential, and that release is an "off response" in physiological conditions. This is also suggested by the experiment outlined in Figure 5, where calcium currents generated by 2 msec presynaptic action potential-like depolarizations were "tail' currents. 

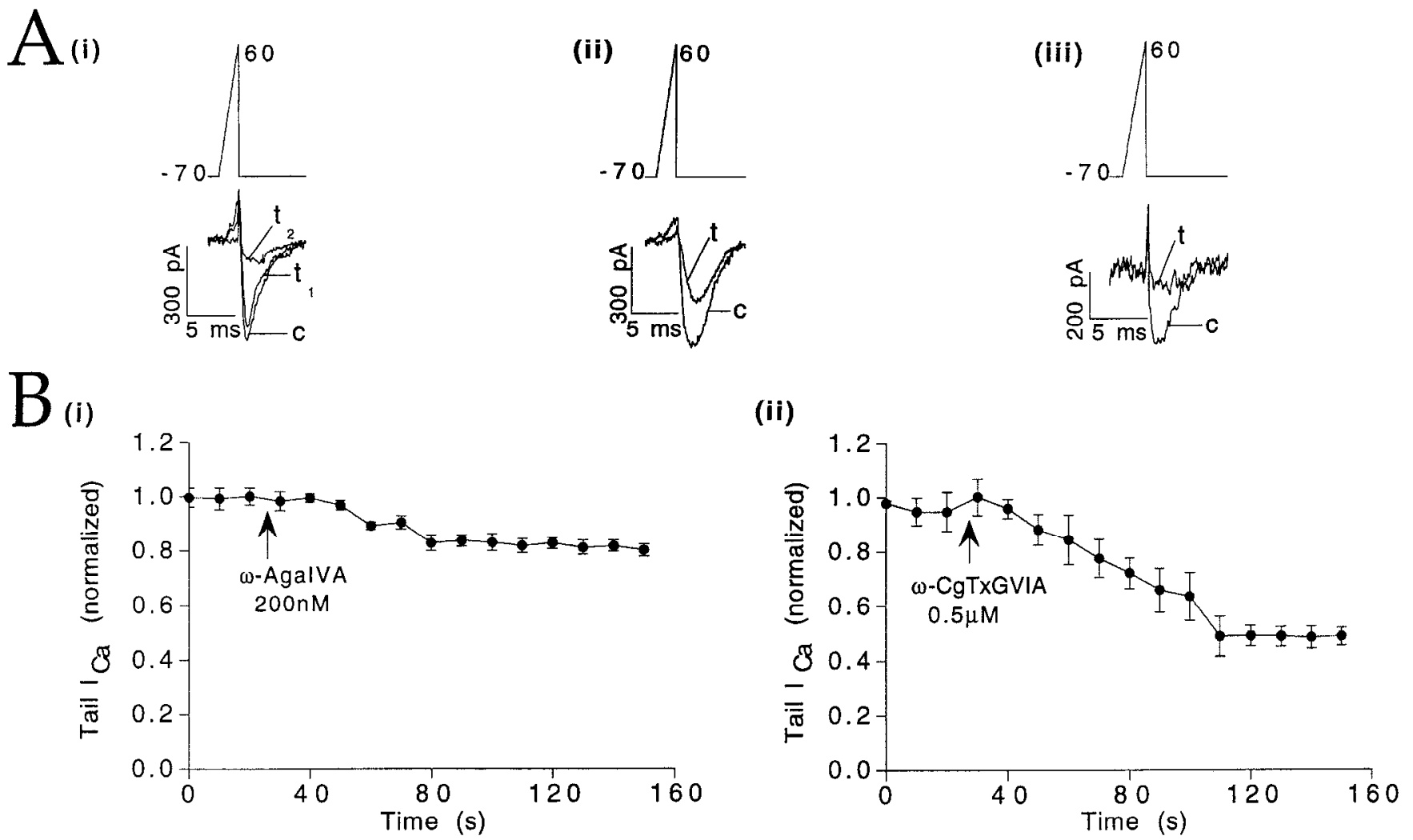

Figure 5. Effects of $\omega$-Aga IVA and $\omega$-CgTx GVIA on calyx calcium tail currents. A, Tail currents from three different calyces. In each case, the calyx was held at $-70 \mathrm{mV}$ and depolarized to $+60 \mathrm{mV}$ with a $2 \mathrm{msec}$ ramp depolarization (top traces). Bottom traces show the tail currents. $c$, Control; $t_{1}=3 \mathrm{~min}$ after application of $200 \mathrm{nM} \omega$-Aga IVA, $t_{2}=3 \mathrm{~min}$ after further application of $2 \mu \mathrm{M} \omega$-CgTx GVIA (i); $t=4 \mathrm{~min}$ after application of $500 \mathrm{nM} \omega$-CgTx GVIA (ii); $t=3 \mathrm{~min}$ after application of $1 \mu \mathrm{M} \omega$-CgTx GVIA (iii). $B$, Time course of effects of $\omega$-Aga IVA ( $i$, average of 4 experiments) and $\omega$-CgTx GVIA ( $i i$, average of 5 experiments) on tail currents. Ordinate: normalized tail currents measured at the peak. Arrows indicate time of toxin application. Error bars are SEMs.

\section{Criteria for distinguishing between the calyx, NM neuron and glial cells}

Recordings were attempted only from calyces that were clearly visible, but because the presynaptic calyx is tightly coupled to the postsynaptic neuron, inadvertent recordings were often made from the NM neuron. Clear differences were observed, however, between currents expressed by the calyx and the NM neuron. These criteria were assumed to be more reliable than visual identification in distinguishing between pre- and postsynaptic recordings. For example, in normal external saline, presynaptic calyces could be distinguished from NM neurons by differences in their pattern of spiking in response to current injection: long current pulses consistently evoked multiple action potentials in the calyx (Fig. 8Ai) and a single one in the NM soma (Fig. 8Aii). When sodium and potassium currents were blocked, calyces and NM neurons were distinguished by the kinetics of their respective calcium currents. In contrast to presynaptic calcium currents (Fig. 6A), those in the postsynaptic NM neuron activated at ca. $-30 \mathrm{mV}$ from a holding potential of $-70 \mathrm{mV}$, and showed two components: one rapidly inactivating, the other sustained (Fig. $8 B)$. The sustained component was partly blocked by $5 \mu \mathrm{M}$ $\omega$-CgTx GVIA and partly by $2 \mu \mathrm{M}$ nifedipine. The transient component showed little sensitivity to either blocker (data not shown). In some cxpcriments, Lucifer ycllow was included in the patch pipette to confirm the recording site and the calcium currents associated with it (Fig. $1 B$ ). Electrophysiological responses were also used to differentiate between calyces and glial cells. Glial cells showed no inward currents in response to voltage-clamp steps, and had small ( $\sim 100 \mathrm{pA}$ maximum amplitude) outward currents in normal external saline.

\section{Discussion}

The large size of the presynaptic terminals made by auditory afferents onto magnocellularis neurons in the chick has enabled us to examine directly the presynaptic calcium currents underlying transmitter release at a glutamatergic synapse in the chick auditory brainstem. Our results show that both the presynaptic calcium current and transmitter release are insensitive to nifedipine (up to $10 \mu \mathrm{M}$ ), but are blocked completely by $1-2 \mu \mathrm{M}$ $\omega$-CgTx GVIA and partially (16-25\%) by 200 nM $\omega$-Aga IVA. Similar effects of these two toxins have been observed on potassium-stimulated influx of calcium in chick brain synaptosomes (Mintz et al., 1992b; Lundy et al., 1994). At many mammalian glutamatergic synapses, however, release appears to be predominantly sensitive to $\omega$-Aga IVA (Turner et al., 1992; Takahashi and Momiyama, 1993; Regehr and Mintz, 1994; Wheeler et al., 1994a,b).

Overlap of block of the calyx calcium current by $\omega$-Aga IVA and $\omega-C g T x$ GVIA

In somata of mammalian central neurons, $\omega$-CgTx GVIA and $\omega$-Aga IVA block calcium currents in a nonoverlapping fashion, suggesting the presence of two distinct types of calcium channels (Mintz et al., 1992a). The existence of an overlap in the 


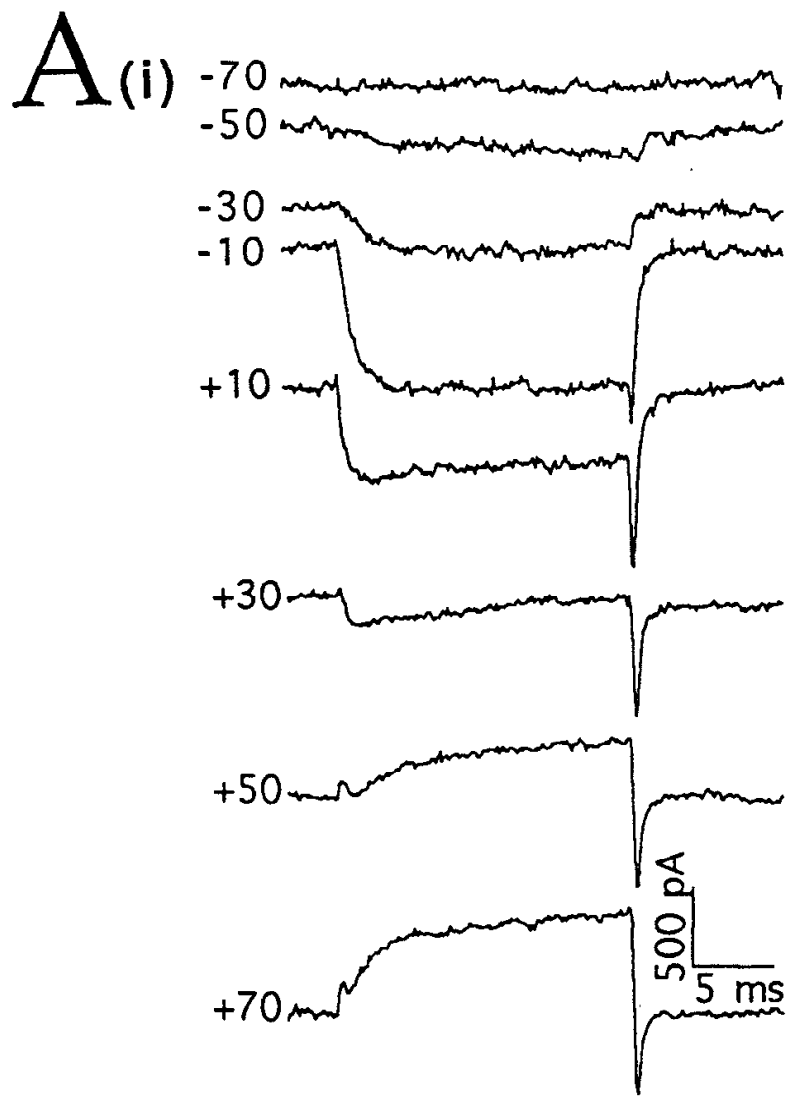

(ii)

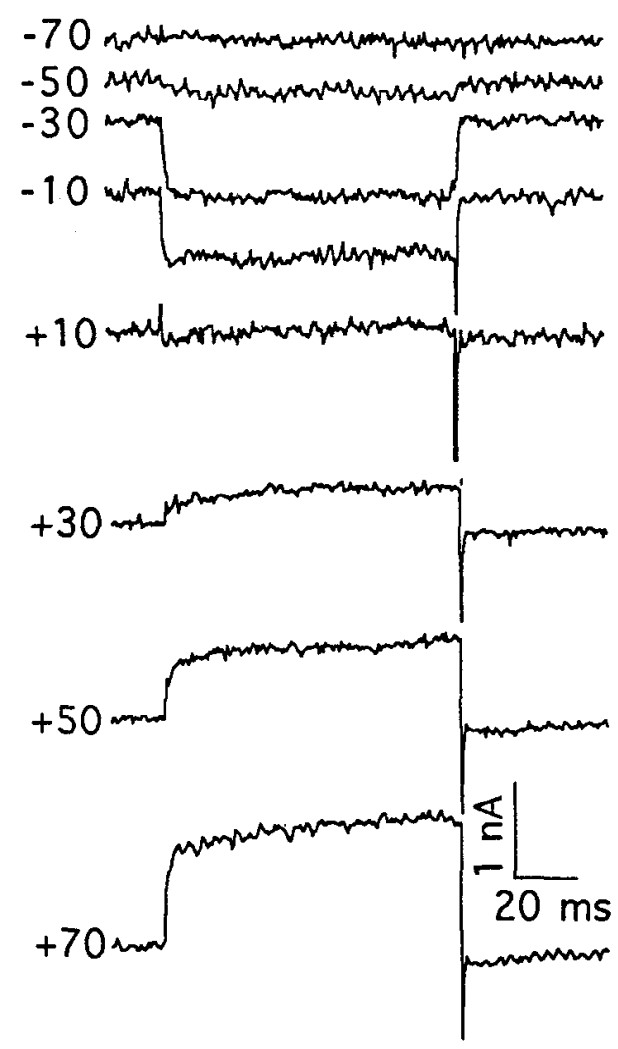

$\mathrm{B}$

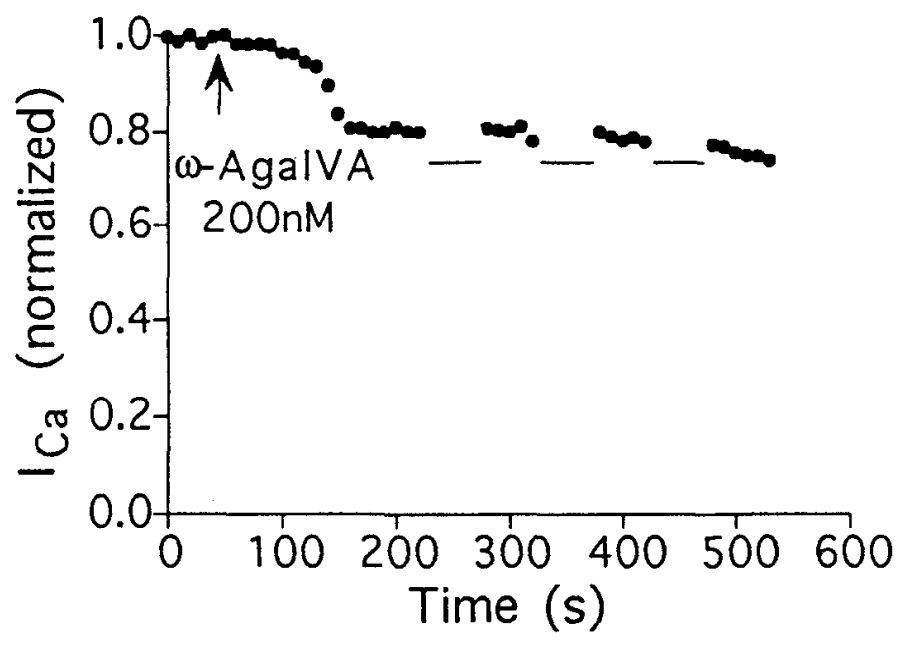

Figure 6. A, Presynaptic calcium currents evoked during $15 \mathrm{msec}$ (i) and $100 \mathrm{msec}$ (ii) step depolarizations from $-70 \mathrm{mV}$ to $+70 \mathrm{mV}$, in $20 \mathrm{mV}$ increments. Recordings shown in $i$ and $i i$ are from two different calyces. Each calyx was held at $-70 \mathrm{mV}$, and depolarized to the voltage (in mV) indicated on the left of each trace. Successive depolarizations were separated by $2 \mathrm{sec}$. Each trace shown is the average of two traces. $B$, Repeated depolarization of a presynaptic calyx during washout of $200 \mathrm{nM} \omega$-Aga IVA. Currents were elicited at $10 \mathrm{sec}$ intervals with $60 \mathrm{msec}$ step depolarizations from $-70 \mathrm{mV}$ to $-10 \mathrm{mV}, \omega$-Aga IVA was applied at the arrow, and the current allowed to reach a steady level, which occurred about 3 min after toxin application. The terminal was then stimulated with a train of conditioning pulses, corresponding to each horizontal bar. Each conditioning train consisted of 10 pulses, $60 \mathrm{msec}$ long, during which the terminal was stepped from $-70 \mathrm{mV}$ to $+80 \mathrm{mV}$. Calcium currents were recorded beginning $100 \mathrm{msec}$ after the end of the conditioning train, and were evoked using the same protocol as before the conditioning train. Rundown of the current is evident, but there was no recovery from the block by w-Aga IVA. 
$\mathrm{A}_{\text {(i) }}$

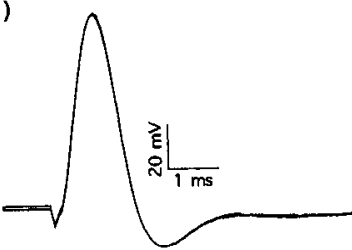

$B_{(i)}$

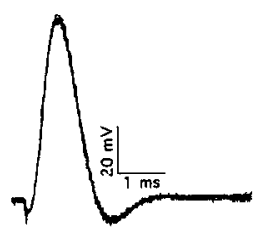

(ii)

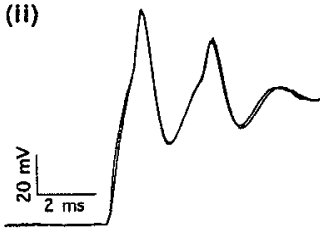

(ii)

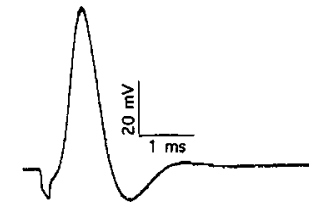

Figure 7. Effects of $\omega$-CgTx GVIA and $\omega$-Aga IVA on pre- and postsynaptic action potentials recorded in current clamp. Ai, Effect of 200 nM $\omega$-Aga IVA on calyx action potentials evoked by extracellular stimulation of a presynaptic axon. Two action potentials, recorded before and $3 \mathrm{~min}$ after toxin application are superimposed. $i$ i, Effect of $2 \mu \mathrm{M}$ $\omega$-CgTx GVIA on action potentials generated by step depolarizations of the calyx. Two traces, recorded before and $2.5 \mathrm{~min}$ after toxin application, are superimposed. $B$ Effect of $200 \mathrm{nM} \omega$-Aga IVA $(i)$ and 2 $\mu \mathrm{M} \omega$-CgTx GVIA (ii) on postsynaptic antidromic action potentials, evoked by extracellular stimulation of the axon of the NM neuron and recorded in the NM soma. Records in both $i$ and $i i$ show the superimposition of an action potential recorded in control conditions with four action potentials, evoked at $1 \mathrm{~min}$ intervals following toxin application.

blocking actions of these two toxins on the presynaptic calcium current at the chick magnocellularis synapse makes the interpretation of our results more difficult. Lundy et al. (1994) reported a $100 \%$ block of potassium-stimulated calcium influx in chick brain synaptosomes by $\omega$-CgTx GVIA and a $45 \%$ block by $\omega$-Aga IVA. Calcium influx into the synaptosomes was also in- hibited by $\omega-\mathrm{CgTx}$ MVIIC (Lundy et. al., 1994), which blocks both $\mathrm{N}$ - and P-type calcium channels in mammalian neurons (Hillyard et al., 1992). Lundy et al. (1994) interpreted this overlap to mean that a single type of calcium channel (an NP type), sensitive to both $\omega$-Aga IVA and $\omega$-CgTx GVIA is present in chick brain synaptosomes. An overlapping block of calcium influx into chick brain synaptosomes has also been reported by Mintz et al. (1992b), who concluded, inspite of the overlap, that two distinct types of calcium channels were present in chick synaptosomes.

We can interpret the overlap observed at the chick magnocellularis synapse in at least two ways. First, it is possible that two distinct calcium channels coexist in the presynaptic terminal and that, even at low concentrations $(1 \mu \mathrm{M}), \omega$-CgTx GVIA has a blocking action on several calcium channels, including nonspecific effects on a channel sensitive to $\omega$-Aga IVA. At micromolar concentrations, $\omega$-CgTx GVIA might be specific for $\mathrm{N}$ type calcium channels in mammalian CNS neurons, while it might target a broader class of calcium channels in the avian CNS. Second, if one assumes that $1-2 \mu \mathrm{M} \omega-\mathrm{CgTx}$ GVIA acts with the same specificity at the magnocellularis synapse as it does in mammalian neurons, then the overlapping effects of $\omega$-CgTx GVIA and $\omega$-Aga IVA might indicate that all the presynaptic calcium channels are specifically blocked by $\omega$-CgTx GVIA (that is, all channels are of a single type), and that $\omega$-Aga IVA causes a partial block of the $\omega$-CgTx GVIA-sensitive channels. Our results do not allow us to resolve this issue at present.

\section{Contributions of the $\omega-C g T x$ GVIA and $\omega$-Aga IVA-sensitive components of the presynaptic calcium current to transmitter release}

The overlapping effects of these toxins on transmitter release may be due to their overlapping effects on the presynaptic calcium current and/or to a nonlinear relationship between the presynaptic calcium current and transmitter release (Augustine et

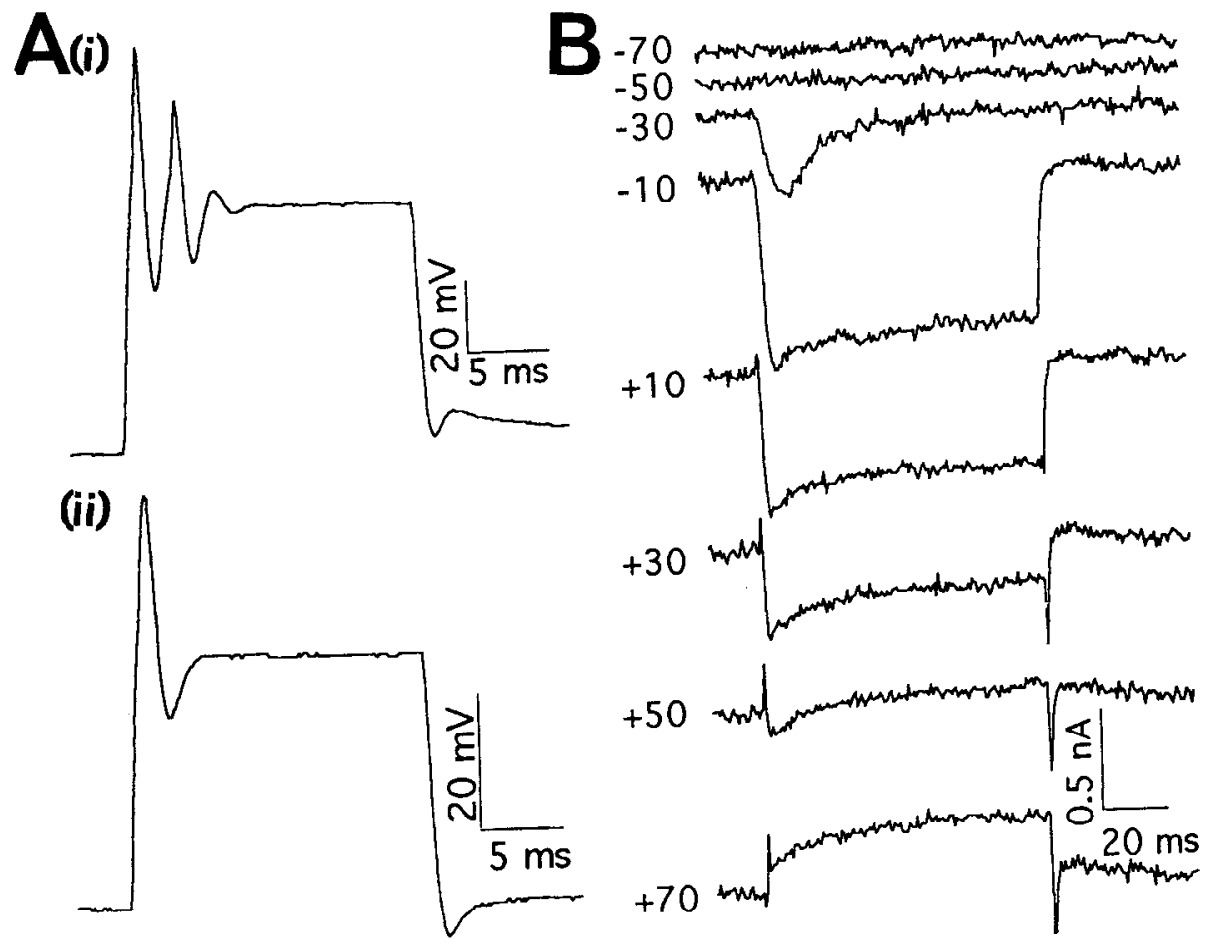

Figure 8. Criteria for distinguishing between recordings made from the calyx and the NM neuron. $A$, Currentclamp recordings of action potentials evoked by depolarizing steps in a calyx (i) and a NM neuron soma (ii). $B$, Calcium currents in a NM neuron. The cell was held at $-70 \mathrm{mV}$ and depolarized to the voltages (in $\mathrm{mV}$ ) indicated on the left of each trace. Each trace is the average of two traces. 
al., 1985b). At the chick magnocellularis synapse, the relationship between the presynaptic calcium current and transmitter release does indeed appear to be nonlinear. If we assume that two distinct presynaptic calcium channels contribute to the total calcium influx that precedes transmitter release, then we can estimate the degree of nonlinearity from the partial block of both the EPSC and the calyx calcium tail current by $500 \mathrm{nM} \omega-\mathrm{CgTx}$ GVIA or $200 \mathrm{nM} \omega$-Aga IVA. This nonlinearity is the value of the power $m$ in the expression $A=(1-a)^{m}$, where $A$ is the fraction of the EPSC remaining in the presence of the toxin, and $a$ is the fraction of the calcium current blocked by the same concentration of toxin (Takahashi and Momiyama, 1993). For $500 \mathrm{nM} \omega-\mathrm{CgTx}$ GVIA, we determined from Figures $2 \mathrm{Bii}$ and 5Bii that $A=0.1$ and $a=0.55$. Therefore, $m=2.88$, suggesting a third-power relationship between the presynaptic calcium current and transmitter release at this synapse. A value of $m=2.38$ was obtained with $200 \mathrm{~nm} \omega$-Aga IVA. An exponent of $n \approx 3-$ 4 has been obtained using fluorescence measurements at the guinea pig hippocampal CA3-CA1 synapse (Wu and Saggau, 1994).

The relative contribution of calcium influx through the $\omega$-Aga IVA and $\omega$-CgTx GVIA sensitive channels to the release of transmitter may depend on the duration of the presynaptic voltage step used to evoke release. $\omega$-Aga IVA blocks about $16 \%$ of the calcium current evoked by $2 \mathrm{msec}$ ramp depolarizations and $25 \%$ of that evoked by $100 \mathrm{msec}$ step depolarizations. This difference suggests that the contribution of the $\omega$-Aga IVA sensitive component to the total presynaptic calcium current might be less when it is evoked naturally, that is, by an action potential that invades the terminal. Under these conditions, the calcium current is mainly a tail current and therefore, release evoked by a natural action potential must be an "off response," occurring after the action potential is over. The tail calcium current is blocked completely by $\omega$-CgTx GVIA but very slightly by $\omega$-Aga IVA. Thus, most of the "relevant" calcium influx in response to a single presynaptic action potential occurs through the $\omega$-CgTx GVIA sensitive calcium channels, which are activated mainly at the end of or after the action potential. When the action potential waveform is broadened, however, or under conditions where there is a prolonged depolarization of the nerve terminal, such as is simulated by rectangular voltage steps, the calcium current activates during the depolarization, and transmitter release would be evoked both during the depolarization (an "on response") as well as after the depolarization (an "off response"). With prolonged depolarizations, one might expect that the contribution of the $\omega$-Aga IVA-sensitive component to the total calcium influx, and thus to transmitter release, would increase. When chick brain synaptosomes are stimulated for several seconds with high potassium, $\omega$-Aga IVA blocks $45-70 \%$ of the ${ }^{45} \mathrm{Ca}^{2+}$ influx (Lundy et al., 1994). Taken together with our results obtained with $2-100 \mathrm{msec}$ presynaptic depolarizations, these results support our hypothesis that calcium influx through the $\omega$-Aga IVA channel increases with the duration of the presynaptic depolarization and suggest that different calcium channels may contribute different amounts of current to the total calcium current, and hence to release, depending on the duration of the presynaptic depolarization.

Comparison of the calyx calcium current with calcium currents in neuronal cell bodies and at other synapses

The electrophysiological properties of the chick magnocellularis calyx calcium current show both similarities and differences with $\mathrm{N}$ - and P-type calcium channels in neuronal somata. The calyx calcium current activates at about $-50 \mathrm{mV}$, which is 10 $20 \mathrm{mV}$ more negative than the activation threshold of other $\omega$-CgTx GVI $\Lambda$-sensitive N-type calcium channels (Fox et al., 1987). Like P-type channels in mammalian neurons (Mintz et al., 1992a; Usowicz et al., 1992), the calyx calcium current shows little voltage-dependent inactivation. It differs from $\mathrm{P}$ type currents, however, in the lack of recovery of block by $\omega$-Aga IVA by repeated depolarizations. Such a lack of recovery from block could result from poor voltage control of the presynaptic calyx, which sometimes extends finger-like processes onto the surface of the postsynaptic soma (Rubel and Parks, 1988). Our records of the presynaptic calcium current (the rapid onset of the current and the fast kinetics of the tail current), however, indicate that there is adequate space clamp of the calyx, at least with voltage steps of $5 \mathrm{msec}$ or longer. Therefore, it is likely that the lack of recovery from block by $\omega$-Aga IVA is a property of the presynaptic calcium channels themselves. In this lack of recovery, the $\omega$-Aga IVA sensitive calyx calcium current resembles the rat brain rbE-II current (Soong et al., 1994), but differs from current through P-type channels in mammalian neurons (Mintz et al., 1992a). It may be similar to Q-type currents (Wheeler et al., 1994a), which are also sensitive to low concentrations of $\omega$-Aga IVA (Wheeler et al., 1994b).

The calyx calcium current has properties which both differ from and resemble those described at other vertebrate and invertebratc synapscs. In rat pituitary ncrve tcrminals, the presynaptic calcium current activates at more depolarized potentials than the calyx current and is affected by $\mathrm{N}-, \mathrm{L}-$, and P-type channel blockers (Lemos et al., 1994). In the chick ciliary ganglion, the presynaptic calcium current is insensitive to nifedipine (Stanley and Atrakchi, 1990) and predominantly blocked by $\omega$-CgTx GVIA (though the block is not complete), and has a high activation threshold (about $-30 \mathrm{mV}$ ) (Stanley and Goping, 1991; Yawo and Momiyama, 1993). The magnocellularis calcium current most closely resembles the presynaptic calcium current at the squid giant synapse in its low threshold of activation and its lack of inactivation (Llinás et al., 1981a; Augustine et al., 1985a) but differs from it in its toxin sensitivity (Charlton and Augustine, 1990).

It is conceivable that the low activation threshold of the presynaptic calcium current at the chick magnocellularis synapse is especially suited to ensure the "fail-proof" release of transmitter needed to accurately convey the phase information of the processed sound signal (Takahashi et al., 1984), perhaps even in situations where the failure of a presynaptic action potential to invade the terminal would result only in a suboptimal depolarization. Thus, calcium channels in nerve terminals, though responsive to many of the same toxins as those in neuronal cell bodies or dendrites, may have acquired, through evolution, electrophysiological properties unique to their role in the release of neurotransmitter.

\section{References}

Augustine GJ, Charlton MP, Smith SJ (1985a) Calcium entry into voltage-clamped presynaptic terminals of squid. J Physiol (Lond) 367: 143-162.

Augustine GJ, Charlton MP, Smith SJ (1985b) Calcium entry and transmitter release at voltage-clamped nerve terminals of squid. J Physiol (Lond) 367:163-181.

Augustine GJ, Charlton MP, Smith SJ (1987) Calcium action in synaptic transmitter release. Annu Rev Neurosci 10:633-693.

Charlton MP, Augustine GJ (1990) Classification of presynaptic cal- 
cium channels at the squid giant synapse: neither T-, L- nor N-type. Brain Res 525:133-139.

Charlton MP, Smith SJ, Zucker RS (1982) Role of presynaptic calcium ions and channels in synaptic facilitation and depression at the squid giant synapse. J Physiol (Lond) 323:173-193.

Fox AP, Nowycky MC, Tsien RW (1987) Kinetic and pharmacological properties distinguishing three types of calcium currents in chick sensory neurones. J Physiol (Lond) 394:149-172.

Hamill OP, Marty A, Neher E, Sakmann B, Sigworth FJ (1981) Pfluegers Arch 391:85-100.

Hillyard DR, Monje VD, Mintz IM, Bean BP, Nadasdi L, Ramachandran J, Miljanich G, Azimi-Zoonooz A, McIntosh JM, Cruz LJ, Imperial JS, Olivera BM (1992) $\Lambda$ new conus peptide ligand for mammalian presynaptic $\mathrm{Ca}^{2+}$ channels. Neuron 9:69-77.

Jhaveri S, Morest DK (1982) Sequential alterations of neuronal architecture in nucleus magnocellularis of the developing chickerr: a Golgi study. Neuroscience 7:855-870.

Katz B (1969) The release of neural transmitter substances. Liverpool: Liverpool UP.

Lemos JR, Wang G, Wang, X, Stuenkel, E, Nordmann JJ, Treistman $\mathrm{SN}$ (1994) Effects of toxins on $\mathrm{Ca}^{2+}$ currents and peptide release from nerve terminals. Ann NY Acad Sci 7:11-29.

Llinás R, Steinberg IZ, Walton K (1981a) Presynaptic calcium currents in squid giant synapse. Biophys J 33:289-322.

Llinás R, Steinberg IZ, Walton K (1981b) Relationship between presynaptic calcium current and postsynaptic potential in squid giant synapse. Biophys $\mathbf{J}$ 33:323-352.

Lundy PM, Hamilton MG, Frew R (1994) Pharmacological identification of a novel $\mathrm{Ca}^{2+}$ channel in chicken brain synaptosomes. Brain Res 643:204-210.

McCobb DP, Beam KG (1991) Action potential waveform voltageclamp commands reveal striking differences in calcium entry via low and high voltage-activated calcium channels. Neuron 7:119-127.

Mintz IM, Adams ME, Bean BP (1992a) P-type calcium channels in rat central and peripheral neurons. Neuron 9:85-95.

Mintz IM, Venema VJ, Swinderek KM, Lee TD, Bean BP, Adams ME (1992b) P-Type calcium channels blocked by the spider toxin $\omega$-AgaIVA. Naturc 355:827-829.

Nemeth EF, Jackson H, Parks TN (1983) Pharmacological evidence for synaptic transmission mediated by non- $N$-methyl-D-aspartate receptors in the avian cochlear nucleus. Neurosci Lett 40:39-44.

Nemeth EF, Jackson H, Parks TN (1985) Evidence for the involvement of kainate receptors in synaptic transmission in the avian cochlear nucleus. Neurosci Lett 59:297-301.

Parks TN (1981) Morphology of axosomatic endings in an avian cochlear nucleus: nucleus magnocellularis of the chicken. $\mathbf{J}$ Comp Neurol 203:425-440.
Pfrieger FW, Veselovsky NS, Gottman K, Lux HD (1992) Pharmacological characterization of calcium currents and synaptic transmission between thalamic neurons in vitro. J Neurosci 12:4347-4357.

Regehr WG, Mintz IM (1994) Participation of multiple calcium channel types in transmission at single clinnbing fiber to Purkinje cell synapses. Neuron 12:605-613.

Rubel EW, Parks TN (1988) Organization and development of the avian brain-stem auditory system. In: Auditory function (Edelman B, et al.), pp 3-92.

Soong TW, Stea A, Hodson CD, Dubel SJ, Vincent SR, Snutch TP (1994) Structure and functional expression of a member of the low voltage-activated calcium channel family. Science 260:1133-1136.

Stanley EF (1993) Single calcium channels and acetylcholine release at a presynaptic nerve terminal. Neuron 11:1007-1011.

Stanley EF, Atrakchi AH (1990) The calcium current in the presynaptic nerve terminal of the chick giant synapse is insensitive to the dihydropyridine nifedipine. Proc Natl Acad Sci USA 87:9683-9687.

Stanley EF, Goping G (1991) Characterization of a calcium current in a vertebrate cholinergic presynaptic nerve terminal. J Neurosci 11: 985-993.

Takahashi T, Moiseff A, Konishi M (1984) Time and intensity cues are processed independently in the auditury systen of the owl. J Neurosci 4:1781-1786.

Takahashi T, Momiyama A (1993) Different types of calcium channels mediate central synaptic transmission. Nature 366:156-158.

Trussell LO, Zhang S, Raman I (1993) Desensitization of AMPA receptors by multiquantal neurotransmitter release. Neuron 10:11851196.

Turner TJ, Adams ME, Dunlap K (1992) Calcium channels coupled to glutamate release identified by $\omega$-Aga-IVA. Science 258:310-313.

Usowicz MM, Sugimori M, Cherksey B, Llinás R (1992) P-type calcium channels in the somata and dendrites of adult cerebellar Purkinje cells. Neuron 9:1185-1199.

Yawo H, Momiyama AJ (1993) Re-evaluation of calcium currents in pre- and postsynaptic neurones of the chick ciliary ganglion. J Physiol (Lond) 460:153-172.

Wheeler DB, Randall A, Tsien RW (1994a) Roles of N-type and Qtype $\mathrm{Ca}^{2+}$ channels in supporting hippocampal synaptic transmission. Science 264:107-111.

Wheeler DB, Tsien RW, Randall A (1994b) Identification of calcium channels that control neurosecretion. Science 266:828-830.

Wu LG, Saggau P (1994) Presynaptic calcium is increased during normal synaptic transmission and paired pulse facilitation, but not longterm potentiation in area CA1 of hippocampus. J Neurosci 14:645655 .

Zhang S, Trussell LO (1994) A characterization of excitatory postsynaptic potentials in the avian nucleus magnocellularis. J Neurophysiol 72:705-718. 